\title{
Low serum selenium concentrations are associated with poor grip strength among older women living in the community
}

\author{
Justine Beck ${ }^{a}{ }^{*}$, Luigi Ferrucci ${ }^{\mathrm{b}}$, Kai Sun ${ }^{\mathrm{a}}$, Jeremy Walston ${ }^{\mathrm{a}}$, Linda P. Fried ${ }^{\mathrm{a}}$, Ravi \\ Varadhan $^{\mathrm{a}}$, Jack M. Guralnik ${ }^{\mathrm{C}}$, and Richard D. Semba ${ }^{\mathrm{a}}$ \\ a Johns Hopkins Medical Institutions, Baltimore, MD, USA \\ b Longitudinal Studies Section, Clinical Research Branch, National Institute on Aging, Baltimore, MD, USA \\ c Epidemiology, Demography and Biometry Branch, National Institute on Aging, Bethesda, MD, USA
}

\begin{abstract}
Aging is associated with a loss of muscle strength, and, in turn, loss of muscle strength has been associated with increased risk of frailty, disability and mortality. The factors that contribute to loss of muscle strength with aging have not been well characterized. Selenium is important in normal muscle function because of its role in selenoenzymes that protect muscle against oxidative damage. We hypothesized that low serum selenium concentrations were associated with poor grip strength. We examined the association between serum selenium and hand grip strength among 676 moderately to severely disabled community-dwelling women in the Women's Health and Aging Study I in Baltimore, Maryland. After adjusting for age, race, body mass index, Mini-Mental Status Examination score, current smoking, hypertension, congestive heart failure and depression, serum selenium was associated with grip strength $(P=0.04)$. This study supports the idea that selenium is important to muscle strength in older women.
\end{abstract}

\section{Keywords}

Aging; muscle; sarcopenia; selenium; strength; women

\section{Introduction}

Aging is characterized by the loss of muscle strength and muscle mass [20]. The cause of the decline in muscle strength and mass is not well understood. In human skeletal muscle, oxidative damage to DNA, proteins, and lipids increases with age $[9,17,19,22]$. The accumulation of mitochondrial and nuclear DNA damage and increase in oxidative stress may contribute to the loss of myocytes and compromise skeletal muscle function [3]. In higher eukaryotes 26 selenoproteins have been identified [27] and in animals alone 25 have been found; although the function of many of these selenoproteins remains unknown [16]. Of the known selenoproteins, there are three known serum selenium containing proteins: extracellular glutathione peroxidase, selenoprotein $\mathrm{P}$ and albumin [21]. Selenium plays an essential role in muscle function [27] and selenoenzymes such as glutathione peroxidase protect myocytes from reactive oxygen species [8]. Selenoprotein $\mathrm{W}$ has been shown to contain reduced glutathione, therefore it may also be involved with antioxidant functions [1].

*Address for correspondence: Justine Beck, 600 N. Wolfe St., Wilmer-Woods Building Room 268, Baltimore, MD 21287, USA. Tel.: +1 443287 5049; Fax: +1 410955 1322; E-mail: jbeck19@jhmi.edu. 
Hand grip strength is often used as an indicator of muscle strength in aging studies, as handgrip strength is correlated with other strength measures such as elbow flexion, knee extension, and trunk extension; thus the use of grip strength is a good model to indicate overall muscle strength [25]. In healthy, middle-aged men, grip strength at baseline was associated with disability and long-term mortality risk $[24,26]$. Grip strength was also a predictor of cause specific and total mortality among older disabled women [25]. These studies both suggest that handgrip strength is associated with mortality; however the potential mechanisms underlying loss of grip strength have not been well characterized. We hypothesized that low serum selenium concentrations were associated with poor grip strength in older adults. To address this hypothesis, we measured serum selenium and grip strength among moderately to severely disabled older women living in the community in Baltimore, Maryland.

\section{Materials and methods}

\subsection{Study subjects}

Subjects in this study were women, aged 65 and older, who participated in the Women's Health and Aging Study I (WHAS I), a population-based study designed to evaluate the causes and course of physical disability in older women living in the community. WHAS I participants were recruited from an age-stratified random sample of women aged 65 years and older selected from Medicare enrollees residing in 12 contiguous zip code areas in Baltimore [11]. Women were screened to identify self-reported physical disability that was categorized into four domains. The domains of disability were ascertained in a 20-30 minute home interview that included questions related to (1) mobility and exercise tolerance, i.e., walking for a quarter of a mile, walking up 10 steps without resting, getting in and out of bed or chairs, (2) upper extremity function, i.e., raising your arms up over your head, using your fingers to grasp or handle, lifting or carrying something as heavy as ten pounds, (3) higher functioning tasks (a subset of instrumental activities of daily living, not including heavy housework, i.e., using the telephone, doing light housework, preparing your own meals, shopping for personal items), and (4) basic self-care tasks (a subset of non-mobility dependent activities of daily living, i.e., bathing or showering, dressing, eating, using the toilet). WHAS I enrolled the one-third most disabled women ages 65 and older, those with difficulty in two or more domains. Of the 1409 women who met study eligibility criteria, 1002 agreed to participate in the study in 1992. There were no major differences in sociodemographic or reported health characteristics between eligible participants and those who declined to participate [11].

\subsection{Data collection}

Standardized questionnaires were administered in the participant's home by trained interviewers. Mini-Mental Status Examination (MMSE) was recorded [11]. Race was assessed in a questionnaire as black, white, or other, current smoking as yes or no, and education as 0$8,9-11,12$ years or more than 12 years as the highest level of formal education achieved. Two weeks after the questionnaires were administered; a trained registered full-time study nurse conducted an examination of each study participant in her home. Each nurse used a standardized protocol that included physical performance measures and a standardized physical examination. Handgrip strength test was assessed by the nurse using a JAMAR hand dynamometer (Model BK-7498, Fred Sammons Inc., Brookfield, IL). Testing was done with the participant in a seated position and the elbow flexed at $90^{\circ}$. Three measurements were taken for each hand and the participant was encouraged to exhibit the best force possible. The handgrip strength test was completed by 919 of the 1002 women enrolled in the study. The reasons for not completing the handgrip strength were as follows: systolic blood pressure of $180 \mathrm{mmHg}$ or greater or diastolic pressure of $110 \mathrm{mmHg}$ or greater $(n=55)$, pain $(n=10)$, tester or participant felt the test was unsafe $(n=11)$, participant refusal $(n=2)$, and other $(n=$ $5)$. 


\subsection{Laboratory studies}

Approximately $75 \%$ of women also consented to phlebotomy performed during a separate visit by a trained phlebotomist who followed a standardized protocol. Further details on the methods and sampling design of the WHAS studies are published elsewhere [11]. There were 1002 women enrolled in the Women's Health and Aging Study I, of whom 739 women participated in the blood drawing and had serum selenium and grip strength measurements at baseline. There were no significant differences in race or body mass index between those who did and did not participate in the blood drawing, but women who did and did not participate in the blood drawing were different by age ( 77.4 vs 80.7 years, respectively, $P<0.0001$ ). Non-fasting blood samples were obtained by venipuncture between 9 AM and 2 PM. Processing, aliquoting, and freezing were carried out at the Core Genetics Laboratory of The Johns Hopkins University School of Medicine following a standardized protocol. Blood samples were delivered to Quest Diagnostics Laboratories (Teterboro, New Jersey) and in part stored continuously at $-70^{\circ} \mathrm{C}$ until the time of analyses for serum selenium.

Serum selenium was measured by graphite furnace atomic absorption spectrometry using a Perkin Elmer AAnalyst 600 with Zeeman background correction. Samples were diluted 1:4 with a triton-X (Sigma Chemical, St. Louis, MO) and nitric acid solution (Fisher Scientific, Pittsburgh, PA), and the matrix modifier was a palladium and magnesium nitrate solution (both Perkin Elmer, Norwalk, CT). The instrument was calibrated daily using known serum selenium standards (UTAK Laboratories, Inc., Valencia, CA). Within-run and between-run coefficients of variation were $5.8 \%$ and $4.8 \%$, respectively. Serum interleukin (IL)-6 was measured using a commercial ELISA (Quantikine Human IL-6, R \& D Systems, Minneapolis, MN).

\subsection{Statistical analysis}

Descriptive statistics were used to characterize the study population and to describe biochemical measurements of serum selenium and grip strength. Body mass index was categorized as underweight $\left(<18.5 \mathrm{~kg} / \mathrm{m}^{2}\right)$, normal range $\left(18.5-24.9 \mathrm{~kg} / \mathrm{m}^{2}\right)$, overweight $(\geqslant$ $\left.25-29.9 \mathrm{~kg} / \mathrm{m}^{2}\right)$ and obese $\left(\geqslant 30 \mathrm{~kg} / \mathrm{m}^{2}\right)$ according to World Health Organization criteria [13]. Linear regression analysis was used to examine the relationship between serum selenium and other factors with grip strength as a continuous outcome variable.

\section{Results}

From the 1002 women enrolled in the Women's Health and Aging Study I, 739 (73.8\%) participated in the blood drawing and $676(67.5 \%)$ women had serum selenium concentrations and grip strength measurements available for analysis. The demographic and disease characteristics of the 676 women at baseline are shown in Table 1 .

Univariate linear regression models were used to examine the relationship between serum selenium, disease and other risk factors associated with grip strength as shown in Table 2. Grip strength was significantly associated with age, race, serum selenium, body mass index, current smoking, MMSE, hypertension, congestive heart failure, and depression. Grip strength was not significantly associated with coronary heart disease, peripheral artery disease, stroke, diabetes mellitus, chronic obstructive pulmonary disease, cancer, or osteoarthritis.

Multivariate linear regression models were used to examine the relationship between serum selenium and grip strength (Table 3 ). After adjusting for age, race, body mass index, and MMSE (model 1), serum selenium was associated with grip strength $(P=0.05)$. In a second model, adjusting for age, race, BMI, MMSE, current smoking, hypertension, congestive heart failure and depression, serum selenium was associated with grip strength $(P=0.04)$. We considered IL-6 to be in the causal pathway, because redox status mediated by selenium is related to 
upregulation of IL-6. In an alternative multivariate model, when IL-6 was added to the same variables used in model 2 , the relationship between selenium and grip strength was attenuated (beta $=1.28, \mathrm{SE}=0.77, P=0.098)$.

\section{Discussion}

The present study shows that low serum selenium is independently associated with poor grip strength among moderately to severely disabled older women living in the community. This finding is consistent with the idea that selenium plays an important role in normal muscle function [27]. A potential biological mechanism by which selenium could contribute to muscle weakness is through maintenance of an optimal concentration of glutathione peroxidase, a key antioxidant selenoenzyme, and/or selenoprotein $\mathrm{W}$. The serum selenium concentrations among women in the present study were lower than that described among older men and women in the Third National Health and Nutrition Examination Survey, [14] but were not as low as serum selenium concentrations that are associated with overt selenium deficiency. More overt human selenium deficiency is associated with a skeletal myopathy and cardiomyopathy $[4,15]$. In ruminant animals, selenium deficiency causes white muscle disease, a condition characterized by muscle weakness and degeneration of skeletal and cardiac muscle [18]. A myopathy similar to white muscle disease has been described in human selenium deficiency [12], and may be related to selenoprotein $\mathrm{W}$ [30]. Severe selenium deficiency is associated with skeletal muscle problems in humans, and this study raises the possibility that more marginal selenium levels, such as that found among community-dwelling adults may contribute to muscle weakness.

Low serum selenium has been shown to be associated with elevated interleukin (IL)-6 [31]. Elevated serum IL-6 levels have been linked with an increased risk of reduced physical function and sarcopenia $[6,23]$ as well as the development of disability $[2,5]$. Thus, selenium may also play a role in muscle weakness due to its relationship with the upregulation of IL-6 through the redox sensitive transcription factor nuclear factor kappa $\mathrm{B}(\mathrm{NF}-\kappa \mathrm{B})$. NF- $\kappa \mathrm{B}$ binding sequences are found in the promoter regions of several cytokine genes associated with inflammatory responses, including IL-6 [10]. Consequently, NF- $\kappa \mathrm{B}$ is a potent activator of the IL-6 promoter [32] and may be involved in the pathway through which selenium contributes to the decline in muscle strength and mass. The relationship between serum selenium and grip strength was attenuated when IL-6 was added to the multivariate analysis, which would be anticipated with IL-6 intermediate in the causal pathway.

The dietary intake of selenium varies widely worldwide, as selenium concentrations in plantbased foods reflect the concentrations of selenium in the soil where the plants were grown. The selenium concentrations in animal sources of food, in turn, depend upon the selenium content of the plants used for forage, or whether animal feed was fortified with selenium. The current dietary requirements for selenium by the Food and Nutrition Board of the Institute of Medicine are based in part upon maintenance of optimal levels of selenoproteins in blood, especially plasma glutathione peroxidase [7]. The selenium requirement for prevention of chronic disease has not yet been definitively determined [29]. The activity of glutathione peroxidase appears to be optimal when serum selenium concentrations are at least $1.27 \mu \mathrm{mol} / \mathrm{L}(100 \mu \mathrm{g} / \mathrm{L})$ or greater [28]. The baseline serum selenium concentrations at which there appeared to be a protective effect of selenium supplementation against cancer in two US trials was 1.34-1.54 $\mu \mathrm{mol} / \mathrm{L}$ (106-147 $\mu \mathrm{g} / \mathrm{L})$ [29]. Except for overt clinical selenium deficiency, the health consequences of an inadequate selenium intake are incompletely understood, and selenium requirements for older adults are largely extrapolations from middle-aged adults [7].

In summary, the present study suggests that low serum selenium concentrations are independently associated with poor grip strength. Further studies are needed to corroborate these observations among men and among less disabled older adults. In addition, longitudinal 
studies may help provide further insight into low serum selenium as a predictor of changes in muscle strength among older adults.

\section{References}

1. Beilstein MA, Vendeland SC, Barofsky E, Jensen ON, Whanger PD. Selenoprotein W of rat muscle binds glutathione and an unknown small molecular weight moiety. Journal of Inorganic Biochemistry 1996;61:117-124. [PubMed: 8576706]

2. Cappola AR, Xue QL, Ferrucci L, Guralnik JM, Volpato S, Fried LP. Insulin-like growth factor 1 and interleukin-6 contribute synergistically to disability and mortality in older women. Journal of Clinical Endocrinology and Metabolism 2003;88:2019-2025. [PubMed: 12727948]

3. Carmeli E, Coleman R, Reznick AZ. The biochemistry of aging muscle. Experimental Gerontology 2002;37:477-489. [PubMed: 11830351]

4. Chariot $P$, Bignani O. Skeletal muscle disorders associated with selenium deficiency in humans. Muscle and Nerve 2003;27:662-668. [PubMed: 12766976]

5. Ferrucci L, Harris TB, Guralnik JM, Tracy RP, Corti MC, Cohen HJ, Penninx B, Pahor M, Wallace R, Havlik RJ. Serum IL-6 level and the development of disability in older persons. Journal of the American Geriatric Society 1999;47:639-646.

6. Ferrucci L, Penninx BW, Volpato S, Harris TB, Bandeen-Roche K, Balfour J, Leveille SG, Fried LP. Change in muscle strength explains accelerated decline of physical function in older women with high interleukin-6 serum levels. Journal of the American Geriatric Society 2002;50:1947-1954.

7. Food and Nutrition Board, Institute of Medicine. Dietary Reference Intakes for Vitamin C, Vitamin E, Selenium, and Carotenoids. National Academy Press; Washington, DC: 2000.

8. Fulle S, Protasi F, Di Tano G, Pietrangelo T, Beltramin A, Boncompagni S, Vecchiet L, Fano G. The contribution of reactive oxygen species to sarcopenia and muscle ageing. Experimental Gerontology 2004;39:17-24. [PubMed: 14724060]

9. Gianni P, Jan KJ, Douglas MJ, Stuart PM, Tarnopolsky MA. Oxidative stress and the mitochondrial theory of aging in human skeletal muscle. Experimental Gerontology 2004;39:1391-1400. [PubMed: 15489062]

10. Ginn-Pease ME, Whisler RL. Redox signals and NF- $\kappa$ B and activation in T cells. Free Radical Biology \& Medicine 1998;25:436-361.

11. Guralnik, JM.; Fried, LP.; Simonsick, EM.; Kasper, D.; Lafferty, ME. The Women's Health and Aging Study: Health and Social Characteristics of Older Women with Disability. Bethesda, MD: National Institute on Aging; 1995. NIH Publication No. 95-4009

12. Ishihara H, Kanda F, Matsushita T, Chihara K, Itoh K. White muscle disease in humans: myopathy caused by selenium deficiency in anorexia nervosa under long term total parenteral nutrition. Journal of Neurology, Neurosurgery \& Psychiatry 1999;67:829-830.

13. James PT, Leach R, Kalamara E, Shayeghi M. The worldwide obesity epidemic. Obesity Research 2001;9(suppl 4):228S-233S. [PubMed: 11707546]

14. Kafai MR, Ganji V. Sex, age, geographical location, smoking, and alcohol consumption influence serum selenium concentrations in the USA: third National Health and Nutrition Examination Survey, 1988-1994. Journal of Trace Elements in Medicine and Biology 2003;17:13-18. [PubMed: 12755496]

15. Klein EA. Selenium: epidemiology and basic science. Journal of Urology 2004;171:S50-S53. [PubMed: 14713754]

16. Kryukov GV, Castellano S, Novoselov SV, Lobanov AV, Zehtab O, Guigo R, Gladyshev VN. Characterization of Mammalian Selenoproteomes. Science 2003;300:1439-1443. [PubMed: 12775843]

17. Lim PS, Cheng YM, Wei YH. Increase in oxidative damage to lipids and proteins in skeletal muscle of uremic patients. Free Radical Research 2002;36:295-301. [PubMed: 12071348]

18. Lofstedt J. White muscle disease of foals. Veterinary Clinics of North America: Equine Practice 1997;13:169-185. 
19. Mecocci P, Fanó G, Fulle S, MacGarvey U, Shinobu L, Polidori MC, Cherubini A, Vecchiet J, Senin U, Beal MF. Age-dependent increases in oxidative damage to DNA, lipids, and proteins in human skeletal muscle. Free Radicals in Biology and Medicine 1999;26:303-308.

20. Morley JE, Baumgartner RN, Roubenoff R, Mayer J, Nair KS. Sarcopenia. Journal of Laboratory and Clinical Medicine 2001;137:231-243. [PubMed: 11283518]

21. Palacios O, Encinar JR, Schaumloffel D, Lobinski R. Fractionation of selenium-containing proteins in serum by multiaffinity liquid chromatography before size-exclusion chromatography-ICPMS. Analalytical and Bioanalytical Chemistry 2006;384:1276-1283.

22. Pansarasa O, Bertorelli L, Vecchiet J, Felzani G, Marzatico F. Age-dependent changes of antioxidant activities and markers of free radical damage in human skeletal muscle. Free Radicals in Biology and Medicine 1999;27:617-622.

23. Payette H, Roubenoff R, Jacques PF, Dinarello CA, Wilson PWR, Abad LW, Harris T. Insulin-like growth factor-1 and interleukin 6 predict sarcopenia in very old community-living men and women: the Framingham Heart Study. Journal of the American Geriatric Society 2003;51:1237-1243.

24. Rantanen T, Guralnik JM, Foley D, Masaki K, Leveille S, Curb JD, White L. Midlife hand grip strength as a predictor of old age disability. Journal of the American Medical Association 1999;281:558-560. [PubMed: 10022113]

25. Rantanen T, Volpato S, Ferrucci L, Heikkinen E, Fried LP, Guralnik JM. Handgrip strength and cause-specific and total mortality in older disabled women: exploring the mechanism. Journal of the American Geriatric Society 2003;51:636-641.

26. Rantanen T, Harris T, Leveille SG, Visser M, Foley D, Masaki K, Guralnik JM. Muscle strength and body mass index as long-term predictors of mortality in initially healthy men. Journal of Gerontology A Biological Sciences Medical Sciences 2000;55:M168-M173.

27. Rederstorff M, Krol A, Lescure A. Understanding the importance of selenium and selenoproteins in muscle function. Cellular and Molecular Life Sciences 2006;63:52-59. [PubMed: 16314926]

28. Sauberlich, HE. Laboratory Tests for the Assessment of Nutritional Status. Vol. 2. Boca Raton: CRC Press; 1999.

29. Thomson CD. Assessment of requirements for selenium and adequacy of selenium status: a review. European Journal of Clinical Nutrition 2004;58:391-402. [PubMed: 14985676]

30. Vendeland SC, Beilstein MA, Chen CL, Jensen ON, Barofsky E, Whanger PD. Purification and properties of selenoprotein $\mathrm{W}$ from rat muscle. The Journal of Biological Chemistry 1993;268:17103-17107. [PubMed: 8349599]

31. Walston J, Xue O, Semba RD, Ferrucci L, Cappola A, Ricks M, Guralnik J, Fried LP. Serum antioxidants, inflammation, and total mortality in older women. American Journal of Epidemiology 2005;163:18-26. [PubMed: 16306311]

32. Zhang J, Johnston G, Stebler B, Keller ET. Hydrogen peroxide activates NF- $\kappa$ B and the interleukin-6 promoter through NF- $\kappa$ B -inducing kinase. Antioxidants \& Redox Signaling 2001;3:493-504.

[PubMed: 11491660] 
Table 1

Characteristics of women in the Women's Health and Aging Study I at baseline $(n=676)$

\begin{tabular}{|c|c|}
\hline Characteristic $^{1}$ & Mean (SD) or \% \\
\hline Age (years) & $77.4(7.8)$ \\
\hline Race (white) (\%) & 72.5 \\
\hline Education $<12$ years $(\%)$ & 63.6 \\
\hline Current smokers $(\%)$ & 10.4 \\
\hline \multicolumn{2}{|l|}{ Body mass index $\left(\mathrm{kg} / \mathrm{m}^{2}\right)$} \\
\hline$<18.5$ & 3.4 \\
\hline $18.5-24.9$ & 23.9 \\
\hline $25.0-29.9$ & 36.1 \\
\hline$\geqslant 30$ & 36.6 \\
\hline MMSE score < $24(\%)$ & 16.7 \\
\hline Plasma selenium $(\mu \mathrm{mol} / \mathrm{L})$ & $1.49(0.23)$ \\
\hline Grip strength (kg) & $18.2(4.9)$ \\
\hline Hypertension (\%) & 56.3 \\
\hline Coronary heart disease $(\%)$ & 23.2 \\
\hline Congestive heart failure (\%) & 10.5 \\
\hline Peripheral artery disease $(\%)$ & 20.9 \\
\hline Stroke $(\%)$ & 5.8 \\
\hline Osteoarthritis (\%) & 52.8 \\
\hline Diabetes mellitus (\%) & 17.2 \\
\hline Chronic obstructive pulmonary disease (\%) & 29.4 \\
\hline Depression $(\%)$ & 16.9 \\
\hline Cancer $(\%)$ & 11.4 \\
\hline
\end{tabular}


Table 2

Univariate linear regression models of serum selenium and other risk factors with grip strength

\begin{tabular}{|c|c|c|c|}
\hline Characteristic & Beta & SE & $P$ \\
\hline Age (years) & -0.237 & 0.022 & $<0.0001$ \\
\hline Race (white) & -1.947 & 0.419 & $<0.0001$ \\
\hline Education $<12$ years & -0.286 & 0.396 & 0.47 \\
\hline Current smokers (\%) & 1.545 & 0.622 & 0.01 \\
\hline \multicolumn{4}{|l|}{ Body mass index $\left(\mathrm{kg} / \mathrm{m}^{2}\right)^{1}$} \\
\hline$<18.5$ & -2.559 & 1.098 & 0.02 \\
\hline $25.0-29.9$ & 1.272 & 0.462 & 0.006 \\
\hline$\geqslant 30$ & 2.620 & 0.460 & $<0.0001$ \\
\hline MMSE & -1.742 & 0.506 & 0.0006 \\
\hline Serum selenium $(\mu \mathrm{mol} / \mathrm{L})$ & 2.280 & 0.799 & 0.0045 \\
\hline Interleukin-6 (pg/mL) & -0.136 & 0.081 & 0.094 \\
\hline Hypertension & 0.827 & 0.383 & 0.03 \\
\hline Coronary heart disease & -0.332 & 0.450 & 0.46 \\
\hline Congestive heart failure & -1.747 & 0.617 & 0.005 \\
\hline Peripheral artery disease & -0.351 & 0.468 & 0.45 \\
\hline Stroke & -1.046 & 0.815 & 0.2 \\
\hline Diabetes mellitus & 0.567 & 0.504 & 0.26 \\
\hline Chronic obstructive pulmonary disease & 0.347 & 0.417 & 0.40 \\
\hline Depression & -1.827 & 0.503 & 0.0003 \\
\hline Cancer & -0.732 & 0.599 & 0.22 \\
\hline Osteoarthritis & 0.197 & 0.381 & 0.61 \\
\hline
\end{tabular}


Table 3

Multivariate linear regression models of serum selenium and other risk factors with grip strength

\begin{tabular}{|c|c|c|c|}
\hline Characteristic & Beta & $\mathbf{S E}$ & $P$ \\
\hline \multicolumn{4}{|l|}{ Model 1} \\
\hline Selenium $(\mu \mathrm{mol} / \mathrm{L})$ & 1.489 & 0.758 & 0.05 \\
\hline Age (years) & -0.182 & 0.024 & $<0.0001$ \\
\hline Race (white) & -1.719 & 0.409 & $<0.0001$ \\
\hline \multicolumn{4}{|l|}{ Body mass index $\left(\mathrm{kg} / \mathrm{m}^{2}\right)$} \\
\hline$<18.5$ & -1.965 & 1.025 & 0.06 \\
\hline $25.0-29.9$ & 1.079 & 0.432 & 0.013 \\
\hline$\geqslant 30$ & 1.574 & 0.442 & 0.0004 \\
\hline MMSE & -0.999 & 0.486 & 0.04 \\
\hline \multicolumn{4}{|l|}{ Model 2} \\
\hline Selenium $(\mu \mathrm{mol} / \mathrm{L})$ & 1.531 & 0.753 & 0.04 \\
\hline Age (years) & -0.170 & 0.024 & $<0.0001$ \\
\hline Race (white) & -1.550 & 0.412 & 0.0002 \\
\hline \multicolumn{4}{|l|}{ Body mass index $\left(\mathrm{kg} / \mathrm{m}^{2}\right)$} \\
\hline$<18.5$ & -2.052 & 1.018 & 0.044 \\
\hline $25.0-29.9$ & 1.077 & 0.431 & 0.013 \\
\hline$\geqslant 30$ & 1.681 & 0.446 & 0.0002 \\
\hline MMSE & -0.977 & 0.537 & 0.07 \\
\hline Current smoking & 1.163 & 0.579 & 0.045 \\
\hline Hypertension & 0.085 & 0.356 & 0.81 \\
\hline Congestive heart failure & -1.156 & 0.559 & 0.039 \\
\hline Depression & -1.496 & 0.465 & 0.0014 \\
\hline
\end{tabular}

